\title{
El aporte de don Andrés Bello a la linguística y filología modernas
}

\author{
Nelson Cartagena* \\ Universidad de Heidelberg, Alemania
}

\begin{abstract}
Resumen
El presente artículo destaca la capital importancia de Andrés Bello en la historia de la gramática española y fundamenta, sobre la base del análisis y de la amplia valoración internacional de sus escritos, su carácter de notable precursor de las más importantes corrientes lingüísticas del siglo XX: el estructuralismo europeo, el estructuralismo norteamericano, la gramática generativa y la lingüística pragmática. Sobre la importancia de Bello para la filología moderna, se remite a sus clásicos trabajos y se expone una inesperada primicia descubierta por el autor del artículo en sus recientes investigaciones. Se trata de la concepción del insigne gramático acerca de la traducción de libretos de ópera dedicada al canto. Su descripción y valoración de las dificultades surgidas de la simbiosis de texto y música en tales textos se adelanta ochenta años a la famosa teoría holística de tales traducciones de Gustav Brecher, la cual, según destacados musicólogos europeos, ha orientado la discusión acerca de la función de dichos traslados interlinguales en Europa durante el siglo XX y la revaloración de esta actividad entre los siglos XV y XIX.
\end{abstract}

Palabras clave: gramática española, lingüística y filología modernas, teoría holística.

* Para correspondencia, dirigirse a: Prof. Dr. Nelson Cartagena (nelson.cartagena@iued. uni-heidelberg.de), Seminar für Ûbersetzen und Domeltschen, Ruprecht-Karls-Universität Heidelberg, Plöck 57 A, D-69117 Heidelberg, Alemania. 


\title{
ANDRES BELLO'S CONTRIBUTION TO MODERN LINGUISTICS AND PHILOLOGY
}

\begin{abstract}
Based on the studies and widespread international appraisal of Andrés Bello's writings, his crucial importance in the history of Spanish Grammar is not only highlighted, but also does this paper manifest his remarkable role as precursor of the major currents of linguistic studies of the $20^{\text {th }}$ century: the European and the American structuralisms, the generative grammar and the pragmatics. By referring to Bello's traditional studies his significance in Modern Philology is clearly shown, and some unique and surprising findings on Bello's idea on the translation of libretti (i.e. the actual vocal parts of opera) are presented by the author of this paper. Bello's characterization and assessment of the difficulties that arise from the symbiosis of text and music in these texts are pronounced about 80 years ahead of Gustav Becher's famous holistic theory on the translation of this type of texts. A theory which, according to distinguished European musicologists, has lead the way in the discussion of the functionality of these distinct interlingual transfers throughout the $20^{\text {th }}$ century, as well as a revaluation of this specific activity during the preceding centuries $\left(15^{\text {th }}-19^{\text {th }}\right.$ century $)$
\end{abstract}

Key words: Spanish grammar, modern linguistics and philology, Holistic theory.

Recibido: 01/12/13 Aceptado: 26/01/14

\section{EL APORTE DE ANDRÉS BELLO A LA GRAMÁTICA Y LINGÜÍSTICA MODERNAS}

1. Don Andrés Bello, nacido en Caracas en 1781 y fallecido en Santiago de Chile en 1865, ha sido en opinión de muchos el intelectual de mayor relieve que ha producido Hispanoamérica y, en la última centuria, sin duda alguna el gramático de la lengua española más celebrado tanto a uno como a otro lado del Atlántico. En el centenario de su nacimiento, como recuerda A. Rosenblat (1975: 16), José Martí, que lo llamaba "poeta egregio", "el pacífico Virgilio de los americanos", "maestro de repúblicas", "señor y legislador de su majestuosa lengua", "en su tiempo el más erudito hablista y el más 
profundo pensador de la tierra en que se hablaba lengua castellana", "el que dio canto a la naturaleza de América y leyes a sus hijos", decía: "Y al elegir, de entre los grandes de América, los fundadores -le elijo a él". Su gramática de la lengua castellana publicada en Valparaíso en 1847 ve en Chile una serie de ediciones y ya a 15 años del fallecimiento de su autor, Rufino José Cuervo, en la introducción a sus famosas notas a dicha gramática, declara que en su sentir es "obra clásica de la literatura castellana". En 1920, Rodolfo Lenz se refiere a ella como "el compendio más completo y concienzudo que existe respecto a la gramática moderna de la lengua española" (1944: 18). En 1951, Amado Alonso (1951: LXXXVI) sostiene lo siguiente acerca de la referida obra:

Sigue hoy mismo siendo la mejor gramática que tenemos de la lengua española. [...] No hay otra que pueda sustituir[la] con provecho [...] en su doble oficio de repertorio de modos de hablar y de cuerpo de doctrina. [...] En este fundamental aspecto la gramática de Bello no es, ni mucho menos, un venerable monumento de museo, como la de Nebrija, 1452, o la de Port Royal, 1660, sino pensamiento vivo y válido. [...] De ninguna gramática europea de su tiempo se puede decir otro tanto. Y es que Bello no solamente seleccionó y organizó las ideas más válidas y consistentes en la primera mitad del siglo XIX, sino que tuvo admirables vislumbres de otras que sólo el siglo XX habría de desarrollar con rigor de sistema. [Su obra] se mantiene en pie [...] no como la mejor gramática castellana a falta de otra mejor, sino como una de las mejores gramáticas de los tiempos modernos en cualquier lengua (Alonso 1951: IX y ss., LXXXVI).

2. El reconocimiento científico de Andrés Bello en España alcanza su punto más alto en la ejemplar edición de su gramática realizada por Ramón Trujillo (1988), que ha venido a llenar una necesidad imperiosa y representa un hito en los estudios bellistas "[al restituir] en su forma prístina [el texto de la gramática de Bello y las notas de Cuervo que] representan para nuestro idioma el repertorio gramatical más serio, ingenioso y erudito que jamás pueda imaginarse" (1988: 10). En consecuencia, ya no extraña a nadie que Emilio Alarcos (1995: 170 y ss.), en su reciente gramática, incorpore en un aspecto central como la terminología de los tiempos verbales la revolucionaria nomenclatura de Bello.

Pero tal vez la demostración más clara del lugar preponderante de Bello en la gramática española actual sea el hecho de que los historiadores de la disciplina lo consideran a menudo como punto de referencia y eje para delimitar ámbitos temporales. Así por ejemplo, José J. Gómez Asencio 
explica que el período escogido como objeto de su tesis doctoral sobre la historia de la gramática y de las categorías verbales en España

... queda enmarcado por dos hitos que me parecen importantes para la historia de las ideas gramaticales en nuestro país: 1771, fecha de publicación de la primera edición de la Gramática de la Real Academia Española [...], 1847, fecha de aparición de la mejor gramática del castellano nunca escrita, la Gramática Castellana de don Andrés Bello (Gómez Asencio 1981: 11).

Y María L. Calero Vaquera aclara que la extensión cronológica de su tesis doctoral Historia de la gramática española (1847-1920): de A. Bello a R. Lenz

... viene delimitada por dos fechas no tan arbitrarias como a primera vista podría parecer: 1847 (año en que se publica la Gramática de la lengua castellana de A. Bello, obra de gran vigencia todavía en la actualidad) y 1920 (fecha algo menos decisiva en nuestra historia gramatical, aunque también digna de ser demarcadora de este estudio, por la aparición de la documentada obra de Rodolfo Lenz, La oración y sus partes) (Calero Vaquera 1986: 9 y ss.).

Respecto de las razones concretas que estos autores arguyen para justificar el valor del pensamiento gramatical de Bello en dichos períodos, resumen su juicio del modo siguiente:

1711-1847 [...] es una época [...] donde conviven dos claras corrientes gramaticales (la de los más apegados a la tradición; la de los reformistas) que acaban interfiriéndose en una tercera corriente mixta (la de los eclécticos) y fundiéndose magistralmente en obras como las de Bello (Gómez Asencio 1981: 356).

Bello, [...] conjugando sabiamente lo más aprovechable de la tradición (tanto grecolatina como racionalista) con sus reflexiones personales, construyó un sólido sistema gramatical difícilmente superable, de donde dimanan -con mayores o menores dudas [deudas?!!!]- las teorías de otros destacados gramáticos del período, tales como Benot, Cejador y Lenz (Calero Vaquera 1986: 269).

Es decir, Bello como suma y síntesis de su tiempo y creador de modelos para las generaciones posteriores. 
Acerca de la validez de las descripciones de Bello en la gramática española de la actualidad, remitimos al detallado recuento de Alonso (1951: XXXIX sig.) y a diversas observaciones sobre el tema ${ }^{1}$.

3. Por nuestra parte deseamos destacar a continuación la figura de don Andrés como precursor de la lingüística moderna.

3.1. Las partes esenciales del prólogo de la gramática de don Andrés Bello no desmerecerían en absoluto como introducción al Curso de lingüística general de Ferdinand de Saussure, lo que es ya de reconocimiento habitual en la hispanística de la actualidad. A este respecto se mencionan las siguientes ideas básicas de Bello:

a) El principio de funcionalidad y el concepto de sistema

Su grámática es funcional por

... explicar lo gramatical por el comportamiento gramatical, la conexión y dependencia mutua de las palabras, es decir, por la función [...] cada clase de palabras se distingue de la otra por las funciones peculiares que desempeña en la oración; las palabras se integran en proposiciones, dentro de las cuales constituyen núcleos (del sujeto o del atributo o predicado), o modifican a esos núcleos o a otros modificadores, o sirven de nexos entre los núcleos o entre los modificadores. Una lengua - dice- es como un cuerpo viviente; su vitalidad no consiste en la constante identidad de elementos, sino en la regular uniformidad de las funciones que éstos ejercen, y de que proceden la forma y la índole que distinguen al todo (Rosenblat 1975: 28 y ss.).

Torres Quintero (1975: 54, y especialmente nota 17) hace notar que el criterio de funcionalidad es el que

... ha dado validez a los estudios estructuralistas de nuestro tiempo, los cuales se fundan en la noción de sistema, desarrollada por Saussure, la que se halla también en germen en el genial autor de la Gramática. [...] Léanse, entre otros, estos pasajes: "El habla de un pueblo es un sistema

\footnotetext{
1 V. entre otros Torres (1975: 58; 51-57), Bosque (1991: 79 y ss.), Rojas (1983: 36-39), Madero (1983), Alarcos (1971: 201), Hernández y Quilis (1973: 75), Rabanales (1966: 235), Barrenechea (1978: §3.16), Lope Blanch (1983: 16).
} 
artificial de signos que bajo muchos respectos se diferencia de los otros sistemas de la misma especie, de que se sigue que cada lengua tiene su teoría particular, su gramática" (Gram., pp. 5-6). Y luego: "Después de un trabajo tan importante como el de Salvá lo único que me parecía echarse de menos era una teoria que exhibiese el sistema de la lengua en la generación y uso de sus inflexiones y en la estructura de sus oraciones, desembarazado de ciertas tradiciones latinas que de ninguna manera le cuadran“" (ibíd. p. 9) (Torres Quintero 1975: 54).

\section{b) El principio de descripción inmanente}

Esta idea clave del estructuralismo saussureano, según la cual la lengua ha de ser descrita como estructura, sin referencia a elementos externos y sobre todo atendiendo a la relación de sus elementos más que a su substancia, tiene en Bello expresión clarísima y variada: "la sola [irrecusable] autoridad en lo tocante a una lengua es la lengua misma", no se deben "aplicar indistintamente a un idioma los principios, los términos, las analogías en que se resumen bien o mal las prácticas de otro", lo que para él significaba fundamentalmente liberar la gramática española de la latina y estudiar la lengua vernácula "como si no hubiese en el mundo otra lengua que la castellana". La independencia que postula entre gramática y lógica ha de entenderse también en igual contexto ("No debemos trasladar ligeramente Ias afecciones de las ideas a los accidents de las palabras").

\section{c) El principio de la prioridad de la descripción sincrónica sobre la dia- crónica}

\section{Al respecto anota Rosenblat:}

Con una clarividencia que parece de nuestros días afirma en la Nota III de su Gramática: "Ver en las palabras lo que bien o mal se supone que fueron, y no lo que son, no es hacer la gramática de una lengua, sino su historia”. ¿No está aquí claramente anticipada la antinomia de Ferdinand de Sausaure entre sincronía y diacronía? (Rosenblat 1975: 28).

3.2. También don Andrés Bello ha sido expresamente declarado precursor del estructuralismo norteamericano por Barry L. Velleman:

Tradicional fallacies, which both Bello and structuralist linguistics attempted to avoid are: 1) The use of preconceptions derived from the grammar of one language (specially Latin) in the discussion of the grammar of another; 2) normativism beyond the bounds of pedagogical 
necessity; and 3) the unnecessary inclusion of historical considerations in the description of synchronic structures (Velleman 1978: 61 y ss.).

3.3. Otros lingüistas modernos leen a Bello desde la perspectiva chomskiana. De este modo, Henk Haverkate cita el siguiente párrafo suyo:

La explicación en que cada hecho tiene su razón particular, que sólo sirve para él, y los diversos hechos carecen de un vínculo común que los enlace y los haga salir unos de otros, y en que por otra parte las excepciones pugnan continuamente con las reglas, no puede contentar al entendimiento. Pero cuando los hechos armonizan, cuando las anomalías desaparecen, y se percibe que la variedad no es otra cosa que la unidad, transformada según las leyes constantes, estamos autorizados para creer que se ha resuelto el problema, y que poseemos una verdadera TEORIA, esto es, una visión intelectual de la realidad de las cosas. La verdad es esencialmente armoniosa (cit. en Haverkate 1982: 99).

Haverkate concluye que este fragmento de Bello "muestra de una manera inequívoca que la moderna gramática generativa no salió de la nada". Y así aparece también en la óptica de variados lectores un Bello generativista (véase Palacios 1983: 173).

Pero tal vez el trabajo más logrado, equilibrado y sugerente dentro de esta perspectiva sea el de María Luisa Rivero (1972), donde se plantea la similaridad del tratamiento de los modos en Bello y de los llamados verbos abstractos en la teoría generativa, por lo cual "aquellos gramáticos que consideran que los estudios de lingüística hispánica deben seguir la tradición marcada por Bello, encontrarán en los métodos de la gramática generativa la técnica que les permite formalizar y ampliar las intuiciones de este insigne lingüista" (Rivero 1972: 55). Rivero muestra que Bello, como Salvá, siguiendo la tradición latina, considera que los verbos en subjuntivo dependen siempre, incluso en oraciones independientes (ojalá te resulte), de un verbo, explícito o sobrentendido. Pero Bello da un paso más y considera también el modo indicativo como subordinado, mencionando incluso cuáles son los verbos que los rigen, por lo cual no considera los modos como categorías sintáctíco-semánticas con significado propio, sino como alteraciones morfológicas resultantes de su dependencia, como

... inflexiones del verbo en cuanto provienen de la influencia o régimen de una palabra o frase a que esté o pueda estar subordinado [...] Dícese $a$ que esté o pueda estar, porque en muchos casos no aparece palabra o frase alguna que ejerza esta influencia sobre el verbo; pero aun entonces hay una idea que lo domina y que pudiera representarse por una proposición 
subordinante. Así en Tus intereses prosperan se concibe, sin que sea menester expresarlo, sé, digo, afirmo que tus intereses prosperan, y cuando enunciamos un deseo diciendo La fortuna te sea propicia se entiende deseo que la fortuna, etc. (Rivero 1972: 56).

Por tanto:

A diferencia de otros gramáticos, Bello no clasifica al subjuntivo como el modo de la subordinación y al indicativo como el modo que aparece en oraciones independientes (lo cual es falso a simple vista) sino que para él ambos modos pertenecen a la subordinación y sus diferencias son atribuibles a los verbos que los rigen. Dando un paso más que Bello podríamos decir que el contenido semántico de duda, posibilidad, etc., que se asocia con el subjuntivo y el contenido de realidad y certeza que se asocia con el indicativo pueden ser asignados a los verbos que los rigen y no a los modos en sí (Rivero 1972: 57).

Ahora bien, George Lakoff en su tesis doctoral de 1965 propone la categoría de "verbo abstracto", equivalente a "implícito" o "sobrentendido", la cual es aplicada por Robin Lakoff en 1968 como fundamento para la definición de los modos en el marco formalizado de un coherente sistema de reglas. Coincidencia sustancial con Bello.

3.4. Y a medida que avanzaba el siglo se fueron reconociendo nuevas facetas precursoras de Bello. Una de ellas la descubre Henk Haverkate, quien ha realizado una "investigación que se centra en una valoración pragmática de la gramática de la lengua castellana desde la perspectiva de la tipología de los actos verbales" (1982: 106). Usando como filtro analítico las categorías básicas de actos verbales asertivos, directivos (impositivos y no impositivos) y expresivos propuesta por Searle (1976), determina entre otros aspectos que "Bello resulta ser un lejano e interesante precursor de la teoría performativa ideada por John Ross hace unos diez años en su artículo 'On declarative sentences' (1970)" (Haverkate 1982: 110) que incide en la ya referida temática de los verbos abstractos. De igual modo, anota que es precursor del llamado análisis factivo, introducido por los Kiparsky, es decir, de la existencia de predicados que presuponen (los factivos) o no (los no factivos) la verdad del estado de cosas expresado en la oración subordinada. Bello afirma, en efecto, que el llamado subjuntivo común expresa emoción del ánimo, que presupone la verdad de lo que se describe en la oración subordinada: En "me alegro de que goces de tan buena salud es claro que se afirma indirectamente que gozas de salud [...] porque este hecho es el que 
produce la alegría". Compárese, por ejemplo, con el predicado no factivo de Supongo que está lloviendo, donde no existe tal presuposición.

3.5. Y de este modo hemos pasado revista a Bello estructuralista europeo, a Bello estructuralista norteamericano, a Bello generativista, a Bello pragmalingüista. Y de continuar este tipo de análisis es muy probable que, para la celebración de los 200 años de la gramática del maestro, tengamos que añadir a Bello psicolingüista, sociolingüista, gramático estratificacional, gramático funcional holandés, gramático sistémico británico y algún otro título que se me escapa. Y es que descriptivistas agudos e inteligencias superiores del pasado y presente siglo llegan a conclusiones semejantes a las alcanzadas por el genio del siglo XIX, cuando se ocupan de problemas idénticos o parecidos. Lo triste es que don Andrés no sea el maestro reconocido y citado por los máximos representantes de las teorías língüisticas modernas referidas, sino el precursor para ellos desconocido de tanta ciencia importante. Y a este respecto debemos lamentablemente aceptar la conclusión de Rafael Torres Quintero cuando, al comprobar algunas importantes coincidencias del pensamiento de Bello con el de Bloomfield, de Jespersen y de Hjelmslev, concluye:

Estos y otros lingüistas de tendencia estructuralista llegaron sin duda a idear sus fecundos planteamientos en fuerza de su discurrir profundo y autónomo sobre el lenguaje humano; pero están muy próximos al pensamiento de Bello, a quien naturalmente no conocieron, o no tuvieron en cuenta, porque mucho de la importancia que pueda tener una teoría científica depende en gran parte del escenario desde donde se dé a conocer (Torres Quintero 1975: 55).

No deseo incitar a los estudiantes e hispanistas a que continúen buscando coincidencias del pensamiento gramatical de Bello con autores contemporáneos que no lo conocen. Pero sí me atrevo a recomendar encarecidamente la atenta lectura de su gramática para solucionar cualquier problema teórico o práctico con que se encuentren en la enseñanza o en el uso de nuestra lengua, así como en la reflexión acerca de ella. Les aseguro que los resultados serán siempre del mayor interés. 


\section{UN EJEMPLO DESCONOCIDO DEL APORTE DE DON ANDRÉS BELLO A LA TEORÍA DE LIBRETOS DE ÓPERA}

1. La importancia de don Andrés Bello en el campo de los estudios filológicoliterarios es ampliamente conocida y valorada. Bástenos citar aquí sus trabajos sobre el origen del romance o epopeya caballeresca y la influencia de la poesía germánica en el romance. Por nuestra parte hemos decidido contribuir a esta mesa redonda con una primicia. Se trata del gran aporte de don Andrés a la teoría de la traducción de ópera, el que hemos descubierto en nuestras últimas investigaciones.

2. Schneider y Schmusch (2009) publican once artículos de musicólogos (entre ellos un germanista, un romanista y un anglista) que se originaron en contribuciones suyas a una mesa redonda realizada en Zürich el 11 de julio de 2007 en el marco del Congreso de la Sociedad Internacional de Musicología (Internationale Gesellschaft für Musikwissenschaft) ${ }^{2}$. Según afirman, hasta muy avanzado el siglo XX la traducción de libretos de ópera fue entendida como mera condición para entender cabalmente el argumento y trama de la obra musical. Pero los trabajos contenidos en el volumen revelan y comprueban que dicha traducción ha constituido siempre de hecho un proceso de transferencia intercultural, cuyo estudio se refiere, por tanto, al proceso mismo de la génesis de la cultura europea moderna, por lo cual constituyen un proyecto de urgente esclarecimiento europeo. Ahora bien, según ellos la idea básica que ha orientado la discusión acerca de la función de la traducción de libretos de ópera en Europa durante el siglo XX fue iniciada por la teoría holística de Gustav Brecher en 1911, quien escribe al respecto:

Las palabras son las que inspiran al compositor su orientación melódica, sus construcciones rítmicas, que lo llevan a elegir determinado tono musical, esa y no otra modulación y timbre (para nombrar solamente los factores principales). Desde Gluck y Mozart, Boieldieu, Auber, Weber hasta Verdi, Wagner y Strauss - en todos los grandes compositores de ópera la palabra ha determinado el tono. [...] En las verdaderas obras maestras de ópera no se puede separar el efecto de palabra y tono, ambos han hecho una alianza inseparable, se han convertido en una nueva unidad. Por lo tanto también la traducción de una ópera escrita en lengua

2 Véase reseña de Cartagena (2012). 
extranjera no puede aspirar sino a conservar ilimitadamente dicha unidad orgánica, en suma, a mantener totalmente también en la lengua meta el efecto y la verdad interna, en suma, la comprensibilidad artística de la obra (traducido de Brecher 1911: 12).

Desde luego que el secular desarrollo y enfrentamiento de culturas vecinas en un espacio geográfico limitado explica la riqueza de los enfoques europeos de la traducción en un ámbito de gran aceptación como el espectáculo operático.

3. Es igualmente comprensible que el traslado interlingual de textos de un nuevo género musical en un pequeño país de América presente horizontes de recepción y discusión mucho más limitados. No obstante, es sorprendente que en la primera opinión polémica documentada sobre el problema en Chile se plantee, 80 años antes que Gustav Brecher, la concepción holística de la simbiosis letra y música de la ópera, que debe respetarse rigurosamente en la traducción de libretos dedicada al canto. En efecto, don Andrés Bello asistió a las primeras representaciones de ópera en Santiago por una compañía italiana de paso en el país, cuyos componentes, al darse cuenta de que el público no entendía la letra, decidieron simplemente traducir muchas arias y cantarlas en español. La reacción del insigne gramático fue en principio de claro rechazo:

Es este [...] un trabajo que, sin facilitar la intelijencia de la obra, perjudica mucho a la espresión i suavidad de la melodía por la falta de correspondencia entre la letra i la música. No basta traducir una aria conservando las mismas ideas i el mismo número de sílabas, es necesario que los acentos naturales del habla coincidan exactamente con los de la modulación musical; de otro modo, el énfasis que el compositor ha colocado sobre una voz importante caerá tal vez sobre una preposición o un artículo, produciendo una discordancia ingrata i chocante. Esto es lo que sucede casi siempre en las versiones, y aun en las obras orijinales, cuando no se atiende a las trabas particulares de la versificación lírica, en que son tan exactos i escrupulosos los italianos, como han sido descuidados los españoles i franceses. Si se comparan las traducciones de Metastasio por Meléndez con sus orijinales, se echará de ver a los pocos versos que el primero de estos dos célebres escritores era músico, i el segundo solamente poeta. La misma falta de intención musical se percibe en casi todas las canciones nacionales de los americanos (en Amunátegui 1888: 83 y ss.). 
Al promediar el siglo, Domingo Faustino Sarmiento apunta en igual dirección que la inferioridad del drama lírico frente al teatro consiste precisamente en la obligada simbiosis de música y letra del primero:

La palabra en el drama marcha tan rápidamente como la pasión que pinta; no así la combinación de los sonidos de la ópera. Para producir su efecto, para expresar las pasiones necesita retener la palabra y subordinarla al compás, a la medida, a la rima que reclama el oído, pues que la música no puede producir sus bellezas sin esta sujeción y estas dilaciones ( $E l$ Progreso, 4 de mayo de 1844, según cita de Cánepa 1976: 239).

3.1. Hernández (1928: 68) opina, sobre la base de la propia experiencia operática chilena, que don Andrés Bello tenía razón solo en parte. Al respecto apunta (ibíd.: 314$)^{3}$ :

Eso de que las óperas italianas fueran cantadas en francés, debía chocar al principio, pero luego se sacaron algunas compensaciones. $\mathrm{Si}$, regularmente, se dijo el cantante italiano somete y hasta sacrifica el drama a la música, el artista francés, por el contrario, más bien sacrifica la parte lírica al éxito dramático (Hernández 1928: 314).

Parecidos comentarios se leen respecto de la temporada de 1885, la cual, según Cánepa (1976: 100) provocó "entre el público y los entendidos la repetida controversia, de si era mejor la ópera italiana o la francesa. La francesa se decía, es más actuada, mientras la italiana se destaca por la afición de sus cultores en lanzar 'los estridentes do de pecho"'. De acuerdo con ello, según se privilegie uno u otro criterio se evalúa de modo diverso la representación de una ópera. De este modo, Pereira Salas (1957: 234) opina que "[La] ópera cómica francesa Los Mosqueteros de la Reina [...] esta vez en versión italiana no logró provocar la hilaridad que desataran los cómicos del grupo francés de 1886", en tanto que Cánepas observa que "Thais [...], a diferencia de años anteriores, [en 1920] se cantó en italiano, lo que pareció revelar muchos efectos nuevos que pasaban inadvertidos en versión francesa debido, tal vez, a la impostación de las voces que dan sonidos más abiertos y vibrantes" (1976: 239). En consecuencia, a la concepción meramente

3 Se refiere a que en la temporada 1877 debuta en Valparaíso La Compañía Lírica Francesa de los Teatros Colón de Buenos Aires, Pedro II de Río de Janeiro y Solís de Montevideo, ofreciendo junto a Le Voyage en Chine, Hamlet, Les Amours du Diable y Haydée ou le Secret, La Traviata, Lucia de Lammermoor y Rigoletto también en francés, lo que reaviva la polémica sobre el problema de la traducción cantada de óperas. 
holística de Andrés Bello se ha añadido el componente intrínseco de la ópera cantada en un escenario, su representación dramática, lo que diversifica la evaluación del traslado interlingual de un libreto. Y don Andrés está como siempre aquí en el comienzo de la discusión, no solo chilena, sino que también europea, aunque en el Viejo Mundo no se haya tomado noticia de ello.

\section{REFERENCIAS BIBLIOGRÁFICAS}

Alarcos, Emilio. 1995. Gramática de la lengua española. Madrid: Espasa Calpe. - 1971. Estudios de gramática functional del español. Madrid: Gredos.

Alonso, Amado. 1951. Introducción a los estudios gramaticales de Andrés Bello. En Andrés Bello. Gramática de la lengua castellana destinada al uso de los americanos, Obras Completas, Tomo IV, pp. IX-LXXXVI. Caracas: Ediciones del Ministerio de Educación.

Amunátegui Reyes, Miguel Luis. 1888. Las primeras representaciones dramáticas en Chile. Santiago: Imprenta Nacional.

Araya, Guillermo (ed.). 1982. Homenaje a Andrés Bello en el bicentenario de su nacimiento (1791-1981). Amsterdam: Universiteit van Amsterdam.

Barrenechea, Ana María. 1978. Las clases de palabras en español como clases funcionales. En Ana María Barrenechea y Mabel Manacorda de Rosetti. Estudios de gramática estructural, pp. 9-26. Buenos Aires: Paidós.

Bello, ANDRÉs. 1988. Gramática de la lengua castellana destinada al uso de los americanos. Con las notas de Rufino José Cuervo, estudio y edición de Ramón Truijillo, I y II. Madrid: Arco/Libros.

Brecher, Gustav. 1911. Opern-Übersetzungen. Berlin: K. Fliegl.

Bosque, Ignacio. 1991. Gramática tradicional y gramática moderna: aspectos de la investigación gramatical sobre el español. Linguistica Antverpiensia XXV: 71-91.

Calero Vaquera, María L. 1986. Historia de la gramática española (1847-1920): de A. Bello a R. Lenz. Marid: Gredos.

CÁnepa Guzmán, Mario. 1976. La ópera en Chile (1839-1930). Santiago: Editorial Andrés Bello.

Cartagena, Nelson. 2012. Reseña de Schneider/Schmusch (2009). LynX. Panorámica de estudios lingüísticos 11: 101-108.

Cuervo, Rufino J. 1988. Notas a la gramática castellana de don Andrés Bello. En Bello 1988: 823-974.

GómÉz Asencio, José J. 1981. Gramática y categorías verbales en la tradición española (1771-1847). Salamanca: Universidad de Salamanca.

Haverkate, Henk. 1982. Los estudios gramaticales de Bello y la teoría de los actos verbales. En Araya 1982: 97-118.

Hernández, César y Antonio Quilis. 1973. Lengua española, I. Madrid: UNED.

HeRnÁNDEZ CORNEJo, RoBerto. 1928. Los primeros teatros de Valparaíso y el desarrollo general de nuestros espectáculos públicos. Valparaíso: Imprenta San Rafael.

Lenz, Rodolfo. 1944. La oración y sus partes. $4 .^{\mathrm{a}}$ ed. Santiago: Nascimento.

Lope Blanch, Juan M. (ed.). 1983. Homenaje a Andrés Bello. Memoria. México, D. F.: UNAM. 
1983. Andrés Bello, paradigma. En Lope Blanch 1983: 9-17.

Madero, Maribel. 1983. Los nexos en la gramática de Andrés Bello. En Lope Blanch 1983: 145-158.

Palacios, Margarita. 1983. Pronombres y adverbios relativos en la obra de Bello. En Lope Blanch 1983: 159-173.

Pereira Salas, Eugenio. 1957. Historia de la música en Chile (1850 a 1900). Santiago: Editorial del Pacífico.

Rabanales, Ambrosio. 1966. Las funciones gramaticales. Boletín de Filología XVIII: 235-276.

Rivero, María Luisa. 1972. La concepción de los modos en la gramática de Andrés Bello y los verbos abstractos en la gramática generativa. Revista de Lingüística Teórica y Aplicada 10: 55-74.

Rojas, Cecilia. Función, clase de palabra y elipsis en la gramática de Bello. En Lope Blanch 1983: 29-39.

Rosenblat, Ángel. 1975. Andrés Bello a los 100 años de su muerte. En Actas del Simposio de Montevideo (enero de 1966). I Congreso de la ALFAL, III Simposio del PILEI, pp. 15-30. México, D. F.

SCHNEIDER, Herbert, y Rainer Schmusch (eds.). 2009. Librettoübersetzung.Interkulturalität im europäischen Musiktheater. Hildesheim/Zürich/New York: Georg Olms Verlag.

SEArLe, John. 1976. A classification of íllocutionary acts. Language and Society 5: 1-13.

Torres Quintero, Rafael. 1975. Modernidad en la gramática de don Andrés Bello. En Actas del Simposio de Montevideo (enero de 1966). I Congreso de la ALFAL, III Simposio del PILEI, pp. 49-59. México, D. F.

Trujillo, Ramón. 1988. Gramática de la lengua castellana, de Andrés Bello, y Notas a la gramática de la lengua castellana de don Andrés Bello, de Rufino José Cuervo. Estudio crítico y edición de Ramón Trujillo. Madrid: Arco/Libros.

Velleman, Barry L. 1978. Structuralist Theory in Bello's 'Gramática'. Hispanic Review 46: 55-64. 